\author{
Historical Studies in Education / Revue d'histoire de l'éducation \\ SPECIAL ISSUE / NUMÉRO SPÉCIAL \\ Education North of 60 / Éducation au nord du 60e
}

\title{
The NWT Archives: \\ A Brief Report from the Trenches
}

\section{W.P.J. Millar}

One day in September 2012, I walked into the NWT Archives, just to explore it. I was in Yellowknife as a tourist, and while my accomplice decided to sit in our hotel room and work on his files, I thought I might as well take a look at the archives. I had already gone to its website (www.nwtarchives.ca) and found it informative and intriguing; so now, with a morning free, I went over to the Prince of Wales Northern Heritage Centre to check it out.

A goldmine, I quickly concluded. Though it took time to work through possibilities for educational history, especially for someone who had never worked at Northern history, I was hooked. (I went back in 2013 to do further work, but by no means did I exhaust the resources.) As readers will quickly see from consulting the website, there is a wealth of documentation available, including textual material, photographs, audio and video recordings, and so on.

It is a pleasant place to do research. The Territorial Archivist, Ian Moir, and his staff are unfailingly helpful. There's ample space for work, and all the necessities are there - a quiet room, up-to-date facilities, photocopying available, the minimum of restrictions on using cameras. One can order documents ahead of time, and the hours are adequate. Having spent a lot of my life in various overseas and Canadian archives, I would rank the NWT archives as one of the best.

And one more thing: researchers should be aware that this is one of the most beautiful settings for an archives that I have ever seen. Located within a museum and cultural centre, on a lake within the city limits, and close to the Legislative Assembly building (with its round Assembly chamber, legislators' chairs arranged in a circle around the periphery for consensual debate and decision, and an impressive polar bear rug in the centre), it's well worth visiting. In summer, during the lunch hour closing, you can walk around the lake and enjoy the view. In winter, during the Caribou Festival, dog sled teams pass by the PWNHC as they compete across the frozen lake. It's a stunning site. 


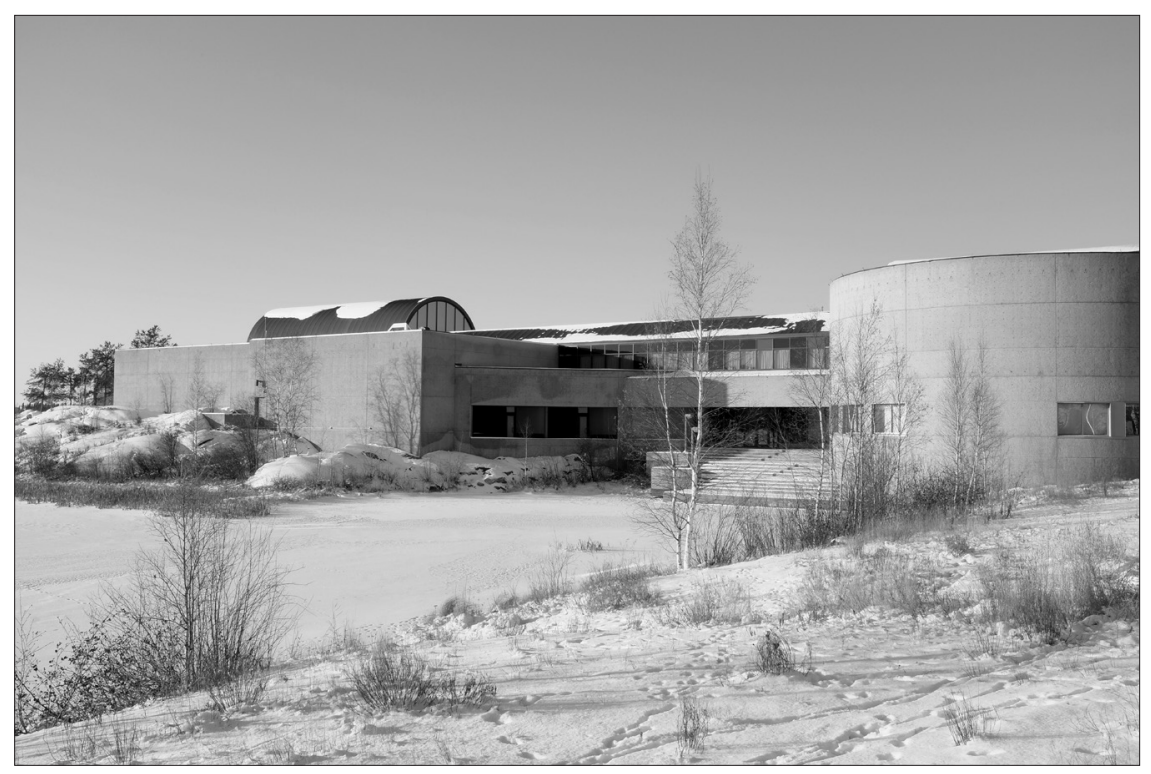

NWT archives, in Prince of Wales Northern Heritage Centre.

Courtesy of Erin Suliak, NWT Archives, November 2014. 